\title{
Elevated Epidermal Growth Factor Receptor Gene Copy Number and Expression in a Squamous Carcinoma Cell Line
}

\author{
Glenn T. Merlino, Young-hua Xu, Nancy Richert, Adrian J. L. Clark, Shunsuke Ishii, \\ Susan Banks-Schlegel, and Ira Pastan \\ Laboratory of Molecular Biology, Division of Cancer Biology and Diagnosis, and Laboratory of Human Carcinogenesis, Division \\ of Cancer Etiology, National Cancer Institute, National Institutes of Health, Bethesda, Maryland 20205
}

\begin{abstract}
The human epidermal growth factor (EGF) receptor is known to be homologous to the v-erb $B$ oncogene protein of the avian erythroblastosis virus. Overexpression of the EGF receptor gene in A431 epidermoid carcinoma cells is due to gene amplification. In this study, a variety of squamous cell carcinomas were examined and one, SCC-15, contained high levels of the EGF receptor as determined by immunoprecipitation via an EGF receptor-specific polyclonal antibody. Using a cloned EGF receptor complementary DNA as a probe, the level of EGF receptor RNA was found to be elevated four-fold in SCC15 relative to normal cultured keratinocytes. When the same probe was used to identify EGF receptor gene fragments on a genomic DNA blot, the SCC-15 cell line was shown to possess an EGF receptor gene copy number amplified four to five times. Gene amplification results in the enhancement in the level of the EGF receptor in several carcinomas and could be responsible for the appearance of the transformed phenotype in these cells.
\end{abstract}

\section{Introduction}

The epidermal growth factor (EGF) ${ }^{1}$ stimulates growth and elicits a wide variety of rapid and delayed responses by binding to high-affinity cell-surface receptors which are 170-kD glycoproteins (1). Recently, EGF receptor peptides have been sequenced and found to be homologous to the avian erythroblastosis virus erb B oncogene product (2), suggesting that the EGF receptor gene is the human c-erb B oncogene. A431 epidermoid carcinoma cells possess a very large number of EGF receptors (3), and the EGF receptor gene is amplified 30-fold (4-6). This amplification is responsible for the overexpression of the EGF receptor protein in these cells (4-6).

A cell culture system has been developed permitting serial cultivation of keratinocytes, whose growth is modulated by EGF (7). Such methods have been used to establish cell lines from squamous cell carcinomas of the oral epithelium (8). Because of the role of EGF in keratinocyte development, we quantified EGF receptor protein and RNA in several squamous

Received for publication 21 November 1984.

1. Abbreviations used in this paper: cDNA, complementary DNA; EGF, epidermal growth factor.

The Journal of Clinical Investigation, Inc.

Volume 75, March 1985, 1077-1079 cell carcinomas. One cell line, SCC-15, was found to contain high amounts of receptor protein and RNA, and a four- to fivefold amplification of the gene.

\section{Methods}

The squamous cell carcinomas established by Rheinwald and Beckett (8) were obtained from, and maintained according to the American Type Culture Collection (Rockville, MD). 1623 was originally designated as SCC-15; 1628 as SCC-25; and 1629 as SCC-9 (8). Normal human esophageal epithelial cells were grown as reported (9). Maintenance of other cell lines was as described elsewhere (10). Proteins were labeled with $\left[{ }^{35}\right.$ S]methionine and immunoprecipitated as previously described (10). PolyA+ RNA was isolated by guanidine isothiocyanate solubilization and $\mathrm{CsCl}$ centrifugation (11), and oligo(dT)-affinity chromatography. RNA (Northern) blotting was performed as described $(11,12)$. High molecular weight DNA was isolated (4) and analyzed by DNA (Southern) blotting $(4,10,13)$. The EGF receptor complementary DNA (cDNA) clone pE7 was constructed and isolated from an A431 cDNA library (11). DNA fragments were ${ }^{32} \mathrm{P}$-labeled by nick translation.

\section{Results}

A large number of cell lines were initially screened for EGF receptor levels by determining their ability to be killed by an EGF-pseudomonas exotoxin conjugate, a technique described previously (10). Several squamous cell carcinomas were found to be relatively sensitive to the EGF-toxin conjugate, including SCC-25, SCC-9, and particularly SCC-15, all derived from the human tongue (8). These three cell lines were labeled with $\left[{ }^{35}\right.$ S $]$ methionine, and their extracts immunoprecipitated with a goat polyclonal antibody to the EGF receptor, affinitypurified as described (10). When compared with A431 cells, which make very large amounts of the EGF receptor, SCC-25 and SCC-9 make moderate amounts and SCC-15 high amounts of the receptor (Fig. 1, lane $a$ vs. $e, g$, and $c$ ). Quantitation of the immunoprecipitation data revealed that SCC-15, SCC-25, and SCC- 9 make 41,15 , and $4 \%$ of the amount of EGF receptor made by $A 431$ cells, respectively.

Because SCC-15 cells had high levels of receptor, polyA+ RNA was isolated from these cells, electrophoretically fractionated on agarose, and analyzed by RNA (Northern) blotting. A cloned A431 cDNA (pE7) encoding the EGF receptor (11) was ${ }^{32} \mathrm{P}$-labeled and used as a hybridization probe to visualize EGF receptor RNAs. Fig. $2 A$ shows that SCC-15 contains both the 10- and 5.6-kilobase species of EGF receptor RNA. The levels are approximately four- to fivefold higher than those found in either KB or A498 kidney carcinoma cells; these cell lines were previously found to possess readily de- 


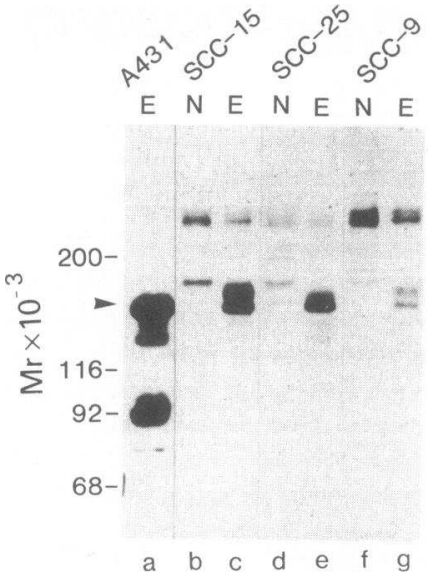

Figure 1. Autoradiograph of electrophoresed ${ }^{35}$ S-labeled EGF receptor protein (arrow) immunoprecipitated by either E, affinity-purified goat polyclonal EGF receptor antibody, or N, normal serum. Molecular weight markers are at left. tectable levels of both receptor RNAs (10). Fig. $2 B$ shows that cultured human epithelial cells contain EGF receptor-specific RNA (HEIA, lane $e$ ) whose levels are higher than an early passage human fibroblast D551 (lane $f$ ), equivalent to A498 (lane $g$ ), but much lower than SCC-15 (lane $b$ ).

To determine if an elevated gene copy number was associated with enhanced expression of the EGF receptor gene in SCC -15 cells, genomic DNA was isolated from normal cultured epithelial cells (HEIA) and SCC-15 cells, digested with HindIII, electrophoretically fractionated, and subjected to DNA blotting analysis. An EGF receptor cDNA (pE7) was used as a hybridization probe to identify receptor DNA fragments. Fig. $3 A$ reveals that the SCC-15 genome contains four- to fivefold amplified EGF receptor gene sequences relative to normal epithelial cells (lane $a$ vs. $b$ ). Analysis of $\beta$-actin gene fragments on the same filter by hybridization to a chick actin cDNA probe indicated that equal amounts of DNA were loaded per well (data not shown). Digested SCC-15 DNA had to be diluted about fourfold (Fig. $3 \mathrm{~B}$, lane $e$ ) to approximate the signal intensity of receptor DNA fragments from SCC-25, SCC-9, and KB cells (lanes $g-i$ ). The KB cell EGF receptor gene is known not to be amplified (10).

\section{Discussion}

It may be significant that A431 carcinoma cells are not unique in their possession of amplified EGF receptor genes. We report here that the EGF receptor gene in squamous cell carcinoma SCC-15 is amplified four- to fivefold relative to normal epithelial

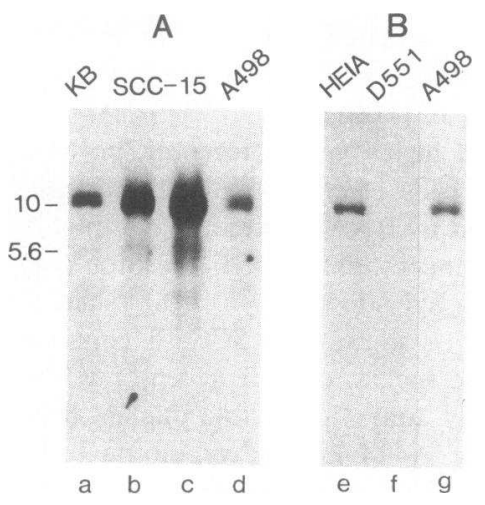

Figure 2. RNA blot analysis of polyA+ RNAs using the ${ }^{32}$ P-labeled EGF receptor cDNA probe pE7. $(A)$ and $(B)$ are autoradiographs from two separate gels. Sizes are in kilobases (left). 5 (lanes $a, b, d$, and $g$ ) or 10 (lanes $c, e$, and $f$ ) $\mu \mathrm{g}$ of RNA were loaded.

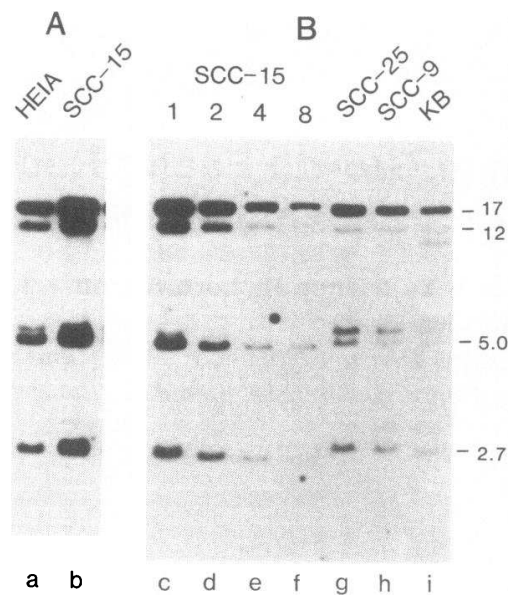

Figure 3. DNA blot analysis of HindIII-digested genomic DNAs using the pE7 probe (see Fig. 2). $(A)$ and $(B)$ are autoradiographs from two separate gels. Sizes are in kilobase pairs (right). $10 \mu \mathrm{g}$ of DNA was loaded except in $(B)$, lanes $d-f$, which represent serial dilutions of the 1623 DNA shown in lane $c$.

cells. The amplification of the EGF receptor gene may cause the initiation or maintenance of the malignant state in some human cells.

Previously, we reported that a variety of transformed cell lines synthesize relatively high amounts of both EGF receptor protein and messenger RNA (10). It is conceivable that a moderate or even a small increase in the level of the EGF receptor leads to a change in the cellular phenotype, as has been demonstrated for the $s r c$ gene product (14). If this hypothesis is correct, then even a minor amplification of the EGF receptor gene copy number could contribute to the onset of tumorigenesis. Hendler and Ozanne (15) have examined lung squamous cell carcinomas and found that they contain a 2.5-5-fold increase in EGF receptor levels.

\section{References}

1. Savage, C. R., and S. J. Cohen. 1972. Epidermal growth factor and a new derivation: rapid isolation procedure and biological and chemical characterization. J. Biol. Chem. 247:7609-7611.

2. Downward, J., Y. Yarden, E. Mayes, G. Scarce, N. Totty, P. Stockwell, A. Ullrich, J. Schlessinger, and M. D. Waterfield. 1984. Close similarity of the epidermal growth factor receptor and v-erb B oncogene protein sequence. Nature (Lond.). 307:521-527.

3. Fabricant, R. N., J. E. DeLarco, and G. J. Todaro. 1977. Nerve growth factor receptor on human melanoma cells in culture. Proc. Natl. Acad. Sci. USA. 74:565-569.

4. Merlino, G. T., Y.-H. Xu, S. Ishii, A. J. L. Clark, K. Semba, K. Toyoshima, T. Yamamoto, and I. Pastan. 1984. Amplification and enhanced expression of the epidermal growth factor receptor gene in A431 human carcinoma cells. Science (Wash. DC). 224:417-419.

5. Ullrich, A., L. Coussens, J. S. Hayflick, T. J. Dull, A. Gray, A. W. Tam, J. Lee, Y. Yarden, T. A. Libermann, J. Schlessinger, J. Downward, E. L. V. Mayes, N. Whittle, M. D. Waterfield, and P. H. Seeburg. 1984. Human epidermal growth factor receptor cDNA sequence and aberrant expression of the amplified gene in A431 epidermal carcinoma cells. Nature (Lond.). 309:418-425.

6. Lin, C. R., W. S. Chen, W. Kruiger, L. S. Stolarsky, W. Weber, R. M. Evans, I. M. Verma, G. N. Gill, and M. G. Rosenfeld. 1984. 
Expression cloning of human EGF receptor complementary DNA: gene amplification and three related messenger RNA products in A431 cells. Science (Wash. DC). 224:843-848.

7. Rheinwald, J. G., and H. Green. 1975. Serial cultivation of strains of human epidermal keratinocytes: the formation of keratinizing colonies from single cells. Cell. 6:331-344.

8. Rheinwald, J. G., and M. A. Beckett. 1981. Tumorigenic keratinocyte lines requiring anchorage and fibroblast support cultured from human squamous cell carcinomas. Cancer Res. 41:1657-1663.

9. Banks-Schlegel, S. P., and C. C. Harris. 1983. Tissue-specific expression of keratin proteins in human esophageal and epidermal epithelium and their cultured keratinocytes. Exp. Cell Res. 146:271280.

10. Xu, Y.-H., N. Richert, S. Ito, G. T. Merlino, and I. Pastan. 1984. Characterization of epidermal growth factor receptor gene expression in malignant and normal human cell lines. Proc. Natl. Acad. Sci. USA. 81:7308-7312.
11. Xu, Y.-H., I. Ishii, A. J. L. Clark, M. Sullivan, R. K. Wilson, D. P. Ma, B. A. Roe, G. T. Merlino, and I. Pastan. 1984. Human epidermal growth factor receptor cDNA is homologous to a variety of RNAs overproduced in A431 carcinoma cells. Nature (Lond.). 309: 806-810.

12. Thomas, P. S. 1980. Hybridization of denatured RNA and small DNA fragments transferred to nitrocellulose. Proc. Natl. Acad. Sci. USA. 77:5201-5205.

13. Southern, E. M. 1975. Detection of specific sequences among DNA fragments separated by gel electrophoresis. J. Mol. Biol. 98:503517.

14. Jakobovits, E. B., J. E. Majors, and H. E. Varmus. 1984. Hormonal regulation of the Rous sarcoma src gene via a heterologous promoter defines a threshold dose for cellular transformation. Cell. 38: 757-765.

15. Hendler, F. J., and B. W. Ozanne. 1984. Human squamous cell lung cancers express increased epidermal growth factor receptors. J. Clin. Invest. 74:647-651. 